\title{
Major predictors and management of small-bowel angioectasia
}

\author{
Atsushi Igawa', Shiro Oka², Shinji Tanaka², Sayoko Kunihara', Makoto Nakano' ${ }^{1}$, Taiki Aoyama \\ and Kazuaki Chayama ${ }^{1}$
}

\begin{abstract}
Background: Small-bowel angioectasias are frequently diagnosed with capsule endoscopy (CE) or balloon endoscopy however, major predictors have not been defined and the indications for endoscopic treatment have not been standardized. The aim of this study was to evaluate the predictors and management of small-bowel angioectasia.
\end{abstract}

Methods: Among patients with obscure gastrointestinal bleeding (OGIB) who underwent both CE and double-balloon endoscopy at our institution, we enrolled 64 patients with small-bowel angioectasia (angioectasia group) and 97 patients without small-bowel angioectasia (non-angioectasia group). The angioectasia group was subdivided into patients with type 1a angioectasia (35 cases) and type 1b angioectasia (29 cases) according to the Yano-Yamamoto classification. Patient characteristics, treatment, and outcomes were evaluated.

Results: Age $(P=0.001)$, cardiovascular disease $(P=0.002)$, and liver cirrhosis $(P=0.003)$ were identified as significant predictors of small-bowel angioectasia. Multivariate logistic regression analysis identified cardiovascular disease (odds ratio 2.86; $95 \%$ confidence interval, 1.35-6.18) and liver cirrhosis (odds ratio 4.81; $95 \%$ confidence interval, 1.79-14.5) as independent predictors of small-bowel angioectasia. Eleven type 1a cases without oozing were treated conservatively, and 24 type 1a cases with oozing were treated with polidocanol injection (PDI). Re-bleeding occurred in two type $1 \mathrm{a}$ cases (6\%). Seventeen type $1 \mathrm{~b}$ cases were treated with PDI and 12 type $1 \mathrm{~b}$ cases were treated with PDI combined with argon plasma coagulation (APC) or clipping. Re-bleeding occurred in five type $1 \mathrm{~b}$ cases $(17 \%)$ that resolved after additional endoscopic hemostasis in all cases. There was one adverse event from endoscopic treatment (1.6\%).

Conclusions: Cardiovascular disease and liver cirrhosis were significant independent major predictors of small-bowel angioectasia. Type 1a angioectasias with oozing are indicated for PDI and type $1 \mathrm{~b}$ angioectasias are indicated for PDI with APC or clipping.

\section{Background}

Small-bowel vascular lesions, especially small-bowel angioectasias, account for a large number of cases of obscure gastrointestinal bleeding (OGIB) [1]. Small-bowel bleeding accounts for $5 \%$ of all gastrointestinal bleeding cases [2], and vascular lesions account for $23-52 \%$ of cases of small-bowel bleeding [3-5]. Small-bowel angioectasias comprise the majority of small-bowel vascular lesions and are found in $30-40 \%$ of OGIB cases [6]. Despite these

\footnotetext{
*Correspondence: oka4683@hiroshima-u.ac.jp

${ }^{2}$ Department of Endoscopy, Hiroshima University, 1-2-3 Kasumi, Minami-ku, Hiroshima 734-8551, Japan

Full list of author information is available at the end of the article
}

facts, the major predictors for small-bowel angioectasia have not been determined.

Angioectasia is a collection of abnormal blood vessels composed of thin tortuous capillaries without an internal elastic membrane. Yano-Yamamoto's [7] accepted endoscopic classification of small-bowel vascular lesions classifies small-bowel angioectasia as a type 1 lesion (Fig. 1). These lesions are further subclassified, as follows: type 1a lesions are characterized by punctate erythema $(<1 \mathrm{~mm})$ with or without oozing, and type $1 \mathrm{~b}$ lesions are characterized by patchy erythema $(2-3 \mathrm{~mm})$ with or without oozing. Fan et al. reported the use of argon plasma coagulation (APC) for the endoscopic treatment of small-bowel 


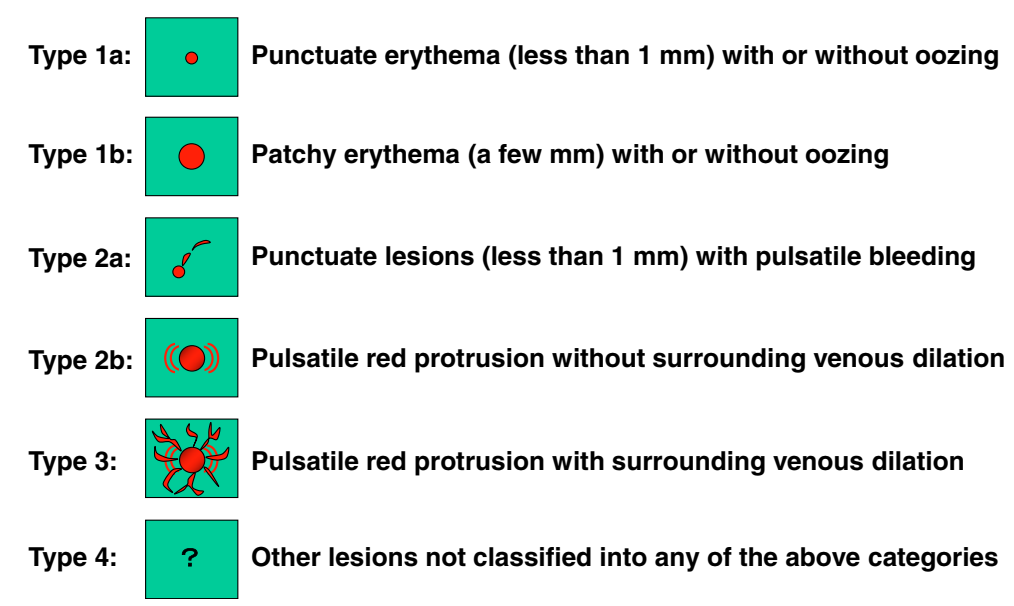

Fig. 1 Endoscopic classification of small-bowel vascular lesions (Yano-Yamamoto classification)

angioectasia [8]. However, there is no consensus on the optimal endoscopic treatment of small-bowel angioectasia.

We analyzed patient characteristics and endoscopic treatments for small-bowel angioectasia cases diagnosed using both capsule endoscopy (CE) and double-balloon endoscopy (DBE) at our institution and followed for at least 1 year. The aim of this study was to determine the major predictors and optimal endoscopic treatment of small-bowel angioectasia.

\section{Methods}

\section{Patients}

A total of 800 patients with OGIB presented to Hiroshima University Hospital between April 2004 and December 2013. Two hundred thirty-eight of those patients underwent both CE and DBE. Sixty-four patients diagnosed with small-bowel angioectasia were assigned to the angioectasia group. Ninety-seven patients without small-bowel angioectasia were assigned to the non-angioectasia group. We excluded 77 patients in whom the entire small bowel had not been visualized. The angioectasia group was subclassified into patients with type $1 \mathrm{a}$ ( 35 cases) and type $1 \mathrm{~b}$ ( 29 cases) angioectasias according to the Yano-Yamamoto classification (Fig. 2). All patients underwent upper and lower gastrointestinal endoscopies prior to $\mathrm{CE}$ and $\mathrm{DBE}$.

The study was conducted in accordance with the Declaration of Helsinki and was approved by the Institutional Review Board of Hiroshima University Hospital. Written informed consent was obtained from all of the patients who participated in the study.

\section{CE procedure}

CE was performed using PillCam SB1 or PillCam SB2 capsules (Given Imaging Ltd, Yokneam, Israel). The capsule was swallowed with a dimethicone solution after an overnight fast, without any other preparation. Patients were allowed to drink clear liquids and eat a light meal $2 \mathrm{~h}$ and $4 \mathrm{~h}$ after swallowing the capsule, respectively. The sensor array and recording device were removed $8 \mathrm{~h}$ after swallowing the capsule. Images were analyzed with Rapid Reader 6 software on a RAPID 5 or 6.5 work station (software and workstation from Given Imaging Ltd).

\section{DBE procedure}

All DBE procedures were performed using the DBE system (FUJIFILM, Saitama, Japan) employing a FUJIFILM EN-450 P5 or EN-450 T5-type endoscope. Per oral insertion of the endoscope required that patients fast for 8-12 h, similar to the preparation for upper gastrointestinal endoscopy. All rectal insertions required a preparation similar to that used for colonoscopy. Patients were lightly sedated with pentazocine $(15 \mathrm{mg})$ and midazolam $(0.05 \mathrm{mg} / \mathrm{kg})$. We selected the oral or rectal route based on the results of CE. If a source of bleeding was not identified during the examination, we marked the smallbowel mucosa with pure carbon at the most distal point.

\section{Strategy of endoscopic treatment for small-bowel angioectasia}

Type 1a lesions without oozing were treated conservatively without any endoscopic intervention. Type 1a lesions with oozing were treated with $1 \%$ polidocanol injection (PDI) in all cases. Type $1 \mathrm{~b}$ lesions were treated with PDI or PDI combined with APC or clipping, according to the condition of the lesions or the endoscope used for treatment. We analyzed the re-bleeding rate and endoscopic treatment related adverse events. Re-bleeding was defined as evidence of recurrent visible gastrointestinal bleeding (melena or hematochezia) with recent negative upper and lower gastrointestinal endoscopies and/or a subsequent decrease in the hemoglobin level by $>2 \mathrm{~g} / \mathrm{dL}$ from baseline. The definition of re-bleeding also included small- 


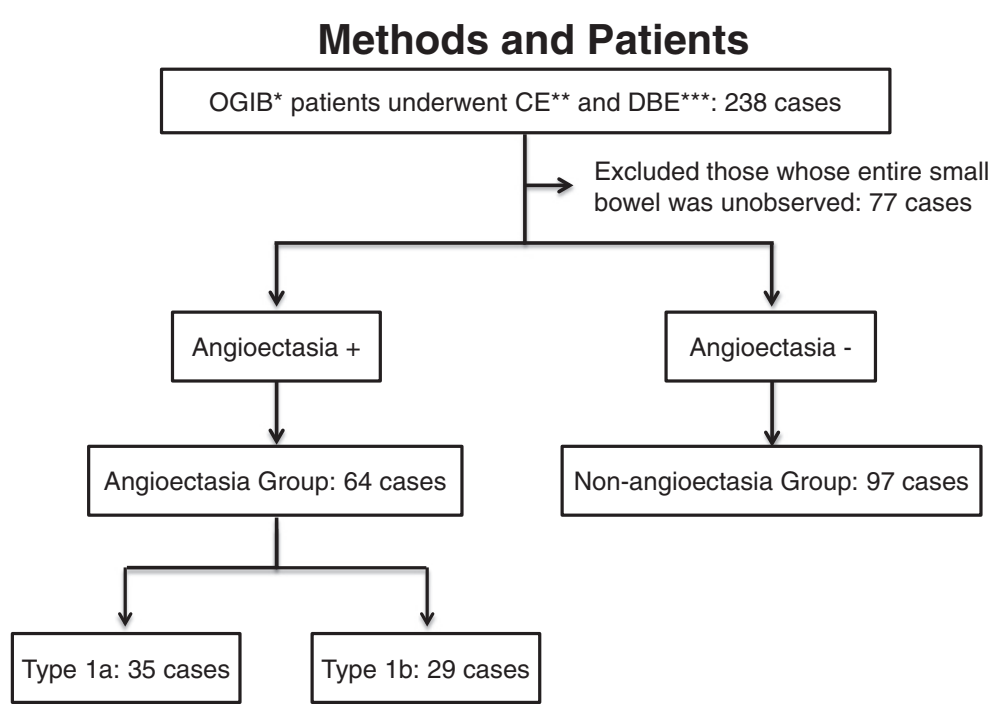

Fig. 2 Flow chart of study patients. * Obscure gastrointestinal bleeding ** Capsule endoscopy *** Double-balloon endoscopy

bowel bleeding from lesions other than those previously treated by endoscopic hemostasis. In addition, follow-up CE or DBE was performed 3-6 months after endoscopic hemostasis for all patients.

\section{Evaluation}

Patient characteristics, including age, sex, bleeding type (overt or occult), drug use (antithrombotic and nonsteroidal anti-inflammatory drugs), and underlying diseases (cerebrovascular disease, cardiovascular disease, chronic renal failure, hypertension, dyslipidemia, diabetes, and liver cirrhosis) were recorded for the two groups. Lesion characteristics for the type 1a and type 1b groups, including number of lesions, location in the small-bowel, outcomes after endoscopic treatment, and re-bleeding rate were evaluated. In addition, we divided the type $1 \mathrm{~b}$ group into two groups according to the treatment methods used (treated with PDI or treated with PDI combined with APC or clipping). The rate of re-bleeding-free survival was calculated and compared between the two groups. The entire small bowel was divided into three parts (upper, middle, and lower) based on CE transit times in accordance with a previous report by $\mathrm{Li}$ et al [9]. The first two parts of the small bowel were considered the jejunum, and the last part was considered the ileum.

\section{Statistical analysis}

Comparisons were performed using the unpaired $t$-test for quantitative data and the chi-squared test for categorical data. A Yates correction or Fisher's exact test was used when required. All tests were two-sided, and a $P$-value < 0.05 was considered statistically significant. Odds ratios (ORs) and $95 \%$ confidence intervals (95\% CIs) were used in the multivariate logistic regression analyses. The re- bleeding-free interval was estimated using the KaplanMeier method. The JMP10 statistical software package (SAS Institute Inc., Cary, NC, USA) was used for all analyses.

\section{Results}

Patient age, cardiovascular disease, and liver cirrhosis were significantly associated with small-bowel angioectasia $(P=0.001, P=0.002$, and $P=0.003$, respectively) (Table 1). On multivariate logistic regression analysis, cardiovascular disease (OR, 2.86; 95 \% CI, 1.35-6.18) and liver cirrhosis (OR, 4.81; $95 \% \mathrm{CI}, 1.79-14.5)$ were significant predictors of small-bowel angioectasia (Table 2). In addition, a separate analysis of the type $1 \mathrm{a}$ and type $1 \mathrm{~b}$ groups revealed no differences between the two groups (Table 3).

Eleven type 1a cases without oozing were treated conservatively without endoscopic intervention, and 24 type 1a cases with oozing were treated endoscopically with PDI. Re-bleeding occurred in two cases (6\%), one was treated conservatively and the other was treated with PDI. The mean time to re-bleeding was 23 days, and in both cases, bleeding occurred from lesions other than those previously treated. One patient had bleeding from a small-bowel arteriovenous malformation and the other had a small-bowel Dieulafoy's lesion. Of the type 1b cases, 17 were treated with PDI and 12 were treated with PDI combined with APC or clipping. Re-bleeding occurred in five cases (17\%), four who had been initially treated with PDI, and one who had been initially treated with PDI combined with APC (Table 4). The mean time to rebleeding was 123 days. Four re-bleeding cases involved previously treated lesions, and one involved a previously untreated lesion. Re-bleeding was controlled conservatively 
Table 1 Characteristics of patients in the angioectasia and non-angioectasia groups

\begin{tabular}{|c|c|c|c|}
\hline $\begin{array}{l}\text { Patient } \\
\text { characteristics }\end{array}$ & $\begin{array}{l}\text { Angioectasia group } \\
(n=64)\end{array}$ & $\begin{array}{l}\text { Non-angioectasia group } \\
(n=97)\end{array}$ & $P$-value \\
\hline \multicolumn{4}{|l|}{ Sex } \\
\hline Male & 39 & 57 & n.s \\
\hline Female & 25 & 40 & \\
\hline \multicolumn{4}{|l|}{ Age (years) } \\
\hline Mean \pm SD & $71.2 \pm 13.9$ & $63.4 \pm 17.3$ & $<0.01$ \\
\hline Median (range) & $75.5(27-87)$ & $66(17-85)$ & \\
\hline$<65$ & 18 & 43 & $<0.05$ \\
\hline$\geqq 65$ & 46 & 54 & \\
\hline \multicolumn{4}{|l|}{ OGIB type } \\
\hline Occult & 15 & 20 & n.s \\
\hline Overt & 49 & 77 & \\
\hline \multicolumn{4}{|l|}{ Drug use } \\
\hline \multicolumn{4}{|l|}{ Antithrombotic } \\
\hline Yes & 20 & 18 & n.s \\
\hline No & 44 & 79 & \\
\hline \multicolumn{4}{|l|}{ NSAIDS } \\
\hline Yes & 6 & 20 & n.s \\
\hline No & 58 & 77 & \\
\hline \multicolumn{4}{|l|}{ Underlying disease } \\
\hline \multicolumn{4}{|c|}{ Cerebrovascular disease } \\
\hline Yes & 6 & 8 & n.s \\
\hline No & 58 & 89 & \\
\hline \multicolumn{4}{|c|}{ Cardiovascular disease } \\
\hline Yes & 27 & 19 & $<0.01$ \\
\hline No & 37 & 78 & \\
\hline \multicolumn{4}{|c|}{ Chronic renal failure } \\
\hline Yes & 6 & 7 & n.s \\
\hline No & 58 & 90 & \\
\hline \multicolumn{4}{|l|}{ Hypertension } \\
\hline Yes & 38 & 43 & n.s \\
\hline No & 26 & 54 & \\
\hline \multicolumn{4}{|l|}{ Dyslipidemia } \\
\hline Yes & 9 & 10 & n.s \\
\hline No & 55 & 87 & \\
\hline \multicolumn{4}{|l|}{ Diabetes } \\
\hline Yes & 15 & 16 & n.s \\
\hline No & 49 & 81 & \\
\hline \multicolumn{4}{|l|}{ Liver cirrhosis } \\
\hline Yes & 15 & 6 & $<0.01$ \\
\hline No & 49 & 91 & \\
\hline
\end{tabular}

Abbreviations: OGIB obscure gastrointestinal bleeding; NSAIDS nonsteroidal anti-inflammatory drugs
Table 2 Multivariate logistic regression analyses of predictors of small-bowel angioectasia

\begin{tabular}{lcll}
\hline Clinical factors & Odds ratio & $95 \%$ confidence interval & $P$-value \\
\hline Liver cirrhosis & 4.81 & $1.79-14.5$ & 0.0028 \\
Cardiovascular disease & 2.86 & $1.35-6.18$ & 0.0066 \\
Age $(\geqq 65)$ & 1.25 & $0.60-2.60$ & 0.550 \\
\hline
\end{tabular}

with additional endoscopic hemostasis in all cases. The Kaplan-Meier curve for post-treatment re-bleeding in type $1 \mathrm{~b}$ angioectasias showed no statistically significant difference between those treated with PDI alone and those treated with PDI combined with APC or clipping $(P=0.29) \quad$ (Fig. 3). One adverse event (1.6 \%) occurred as a result of endoscopic treatment in a patient who developed an ulcer after PDI. This patient recovered with conservative treatment.

\section{Discussion}

The etiology of gastrointestinal angioectasia remains unclear. Regula et al. suggested that a neurohormonal abnormality, in which sympathetic nerve stimulation occurs in response to chronic hypoperfusion, leads to relaxation of intestinal vascular smooth muscle, causing local vascular overload, dilation, and eventually, permanent angioectasia [10]. Junquera et al. reported that the overexpression of angiogenic factors, such as basic fibroblast growth factor and vascular endothelial growth factor, seems to play a pathogenic role in the development of angioectasia [11, 12].

In this study, cardiovascular disease and liver cirrhosis were independent predictors of small-bowel angioectasia. Aortic stenosis [13], chronic renal failure [14], and von Willebrand disease [15] have all been associated with gastrointestinal angioectasia. Hemorrhagic gastrointestinal angioectasia associated with aortic stenosis has been reported as Heyde's syndrome [13]. In the present study, there were four patients in the angioectasia group (6\%) who had aortic stenosis. Additionally, portal hypertensive enteropathy (PHE) associated with portal hypertension in patients with liver cirrhosis has been reported to be a major cause of gastrointestinal bleeding [16]. The endoscopic findings for PHE have been described as red spots, erosions, angioectasia, villous edema, and varices. The presumed cause is blood-flow stasis associated with portal hypertension however, the pathogenesis remains unknown. De Palma et al. conducted a CE-based study and found PHE in $67 \%$ of patients with liver cirrhosis [17]. We previously reported the use of CE to diagnose PHE, especially in patients with Child-Pugh class B or C, ascites, and portal hypertensive gastropathy in patients with compensated liver cirrhosis and portal hypertension [18]. In addition, previously reported major predictors of PHE were the presence of a left gastric vein and splenorenal shunts [19]. Therefore, we believe that patients with OGIB 
Table $\mathbf{3}$ Comparison of patient's characteristics between type $1 \mathrm{a}$ and $1 \mathrm{~b}$ angiectasias

\begin{tabular}{|c|c|c|c|}
\hline \multirow{2}{*}{$\begin{array}{l}\text { Patient } \\
\text { characteristics }\end{array}$} & \multicolumn{2}{|l|}{ Angioectasia } & \multirow[t]{2}{*}{$P$-value } \\
\hline & Type 1a $(n=35)$ & Type 1b $(n=29)$ & \\
\hline \multicolumn{4}{|l|}{ Sex } \\
\hline Male & 22 & 17 & n.s \\
\hline Female & 13 & 12 & \\
\hline \multicolumn{4}{|l|}{ Age (years) } \\
\hline Mean $\pm S D$ & $69.3 \pm 16.4$ & $73.5 \pm 10.8$ & n.s \\
\hline Median (range) & $75(27-87)$ & $78(42-86)$ & \\
\hline$<65$ & 12 & 6 & n.s \\
\hline$\geqq 65$ & 23 & 23 & \\
\hline \multicolumn{4}{|l|}{ OGIB type } \\
\hline Occult & 9 & 6 & n.s \\
\hline Overt & 26 & 23 & \\
\hline \multicolumn{4}{|l|}{ Drug use } \\
\hline \multicolumn{4}{|l|}{ Antithrombotic } \\
\hline Yes & 10 & 10 & n.s \\
\hline No & 25 & 19 & \\
\hline \multicolumn{4}{|l|}{ NSAIDS } \\
\hline Yes & 3 & 3 & n.s \\
\hline No & 32 & 26 & \\
\hline \multicolumn{4}{|l|}{ Underlying disease } \\
\hline \multicolumn{4}{|c|}{ Cerebrovascular disease } \\
\hline Yes & 3 & 3 & n.s \\
\hline No & 32 & 26 & \\
\hline \multicolumn{4}{|c|}{ Cardiovascular disease } \\
\hline Yes & 14 & 13 & n.s \\
\hline No & 21 & 16 & \\
\hline \multicolumn{4}{|c|}{ Chronic renal failure } \\
\hline Yes & 3 & 3 & n.s \\
\hline No & 32 & 26 & \\
\hline \multicolumn{4}{|l|}{ Hypertension } \\
\hline Yes & 18 & 19 & n.s \\
\hline No & 17 & 10 & \\
\hline \multicolumn{4}{|l|}{ Dyslipidemia } \\
\hline Yes & 4 & 5 & n.s \\
\hline No & 31 & 24 & \\
\hline \multicolumn{4}{|l|}{ Diabetes } \\
\hline Yes & 7 & 7 & n.s \\
\hline No & 28 & 22 & \\
\hline \multicolumn{4}{|l|}{ Liver cirrhosis } \\
\hline Yes & 8 & 7 & n.s \\
\hline No & 27 & 22 & \\
\hline
\end{tabular}

Abbreviations: OGIB obscure gastrointestinal bleeding; NSAIDS nonsteroidal anti-inflammatory drugs
Table 4 Comparison of lesion characteristics between type 1a and $1 \mathrm{~b}$ angioectasias

\begin{tabular}{|c|c|c|c|}
\hline \multirow[t]{2}{*}{ Lesion characteristics } & \multicolumn{2}{|l|}{ Angioectasia } & \multirow[t]{2}{*}{$P$-value } \\
\hline & Type 1a $(n=35)$ & Type 1b $(n=29)$ & \\
\hline \multicolumn{4}{|l|}{ Number } \\
\hline Single & 20 & 18 & \multirow[t]{2}{*}{ n.s } \\
\hline Multiple & 15 & 11 & \\
\hline \multicolumn{4}{|c|}{ Localization of the small-bowel } \\
\hline Upper & 12 & 13 & \multirow[t]{3}{*}{ n.s } \\
\hline Middle & 12 & 10 & \\
\hline Lower & 11 & 6 & \\
\hline \multicolumn{4}{|l|}{ First treatment } \\
\hline Follow up & 11 & 0 & \\
\hline PDI & 24 & 17 & \\
\hline PDI + APC or clipping & 0 & 12 & \\
\hline $\begin{array}{l}\text { Re-bleeding after } \\
\text { treatment, } \mathrm{n}(\%)\end{array}$ & $2(6 \%)$ & $5(17 \%)$ & \multirow[t]{4}{*}{ n.s } \\
\hline Present lesion & 0 & 4 & \\
\hline New other lesion & 2 & 1 & \\
\hline Days to re-bleeding & 23 & 123 & \\
\hline $\begin{array}{l}\text { Follow-up period, mean } \pm \\
\text { SD [months] }\end{array}$ & $54 \pm 30$ & $53 \pm 25$ & n.s \\
\hline
\end{tabular}

with cardiovascular disease and/or liver cirrhosis should undergo CE and/or DBE to evaluate possible bleeding from small-bowel angioectasia.

The clinical usefulness of $\mathrm{CE}$ for the evaluation of OGIB has been previously reported [20,21], and CE has become the initial diagnostic choice for the evaluation of patients with OGIB who do not require emergency hemostatic intervention. Small-bowel angioectasias may be easily missed by CE because of their small size; however, we have reported increased detection rates with the use of flexible spectral imaging color enhancement (FICE) [22, 23]. Maeda et al. also reported that FICE 3 was useful for the differential diagnosis of red spots and angioectasia in the smallbowel [24]. In addition, we compared the diagnostic capability of CE and DBE to detect small-bowel lesions in patients with OGIB who had their entire small bowel visualized. The diagnostic concordance rates for $\mathrm{CE}$ and $\mathrm{DBE}$ were high for small-bowel lesions, and when results varied, it was due to false-negative CE results [25]. Postga et al. reported that false- negative cases with $\mathrm{CE}$ were more typically seen with upper small-bowel lesions [26]. Detailed observation is necessary, and repeat CE or DBE should be performed when bleeding persists despite a previously negative CE results in patients with OGIB.

Endoscopic injection sclerotherapy with polidocanol has been used for endoscopic hemostasis in patients with esophageal varices [27] and gastric ulcers with excellent results [28]. Okano et al. reported the early and late 


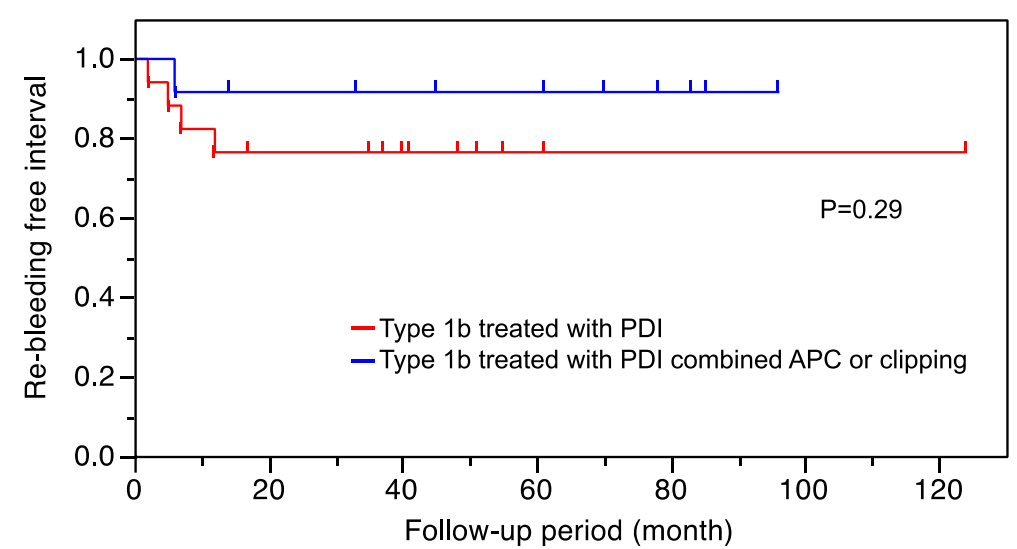

Fig. 3 Kaplan-Meier curve for post treatment re-bleeding according to treatment for patients with type 1b angioectasia. PDI, polidocanol injection; APC, argon plasma coagulation

hemostatic properties of polidocanol from research conducted in dogs. The early hemostatic effects were the result of pressure on the blood vessels with associated interstitial edema and thrombosis formation in small blood vessels, and the late hemostatic effects were due to thrombus formation from vascular inflammation [29]. Takeuchi et al. reported that the effects of PDI were limited to the submucosal layer and that deeper penetration and perforation after PDI did not occur [30].

Re-bleeding in patients with type 1a angioectasia was secondary to other vascular lesions that had not been previously treated. As there is a possibility of missing small lesions, such as Dieulafoy's lesions, in the small bowel, we performed a detailed follow-up observation because of the possibility of heterochronic multiple small-bowel vascular lesions. In contrast, re-bleeding occurred in five patients with type $1 \mathrm{~b}(17 \%)$, and, in four of these cases, bleeding occurred in previously treated lesions. Fan et al. reported that the rate of re-bleeding from previously treated smallbowel angioectasias was about $25 \%$ and that advanced age was a risk factor for re-bleeding [8]. Rahmi et al. also reported in a long-term follow-up study that cardiovascular disease was an independent risk factor for re-bleeding in patients with OGIB with small-bowel angioectasia treated by DBE [31]. In the present study, endoscopic treatments successfully treated type $1 \mathrm{a}$ angioectasias. Type $1 \mathrm{~b}$ angioectasias treated with PDI were more likely to have re-bleeding compared to type $1 \mathrm{~b}$ angioectasias treated with PDI combined with APC or clipping, but the difference was not statistically significant, likely due to the small number of cases. PDI combined with APC or clipping should be considered in type $1 \mathrm{~b}$ angioectasia because PDI alone may not be efficacious. Therefore, it appears that the appropriate endoscopic treatment method is determined according to the type of small-bowel angioectasia. In addition, since all rebleeding cases occurred within 1 year, we recommend strict observation for 1 year after endoscopic treatment.
Our study had some limitations. First, it was a retrospective study, and therefore, a selection bias was inevitable. Second, the study included patients from a single center only. Therefore, a large-scale, prospective study is needed to address these limitations.

\section{Conclusions}

Cardiovascular disease and liver cirrhosis were significant independent major predictors of small-bowel angioectasia. In the management of small-bowel angioectasia, type 1a lesions without oozing do not require endoscopic treatment. However type 1a angioectasias with oozing are indicated for PDI, and type $1 \mathrm{~b}$ angioectasias are indicated for PDI combined with APC or clipping.

\section{Abbreviations}

APC: Argon plasma coagulation; CE: Capsule endoscopy; Cl: Confidence interval; DBE: Double-balloon endoscopy; FICE: Flexible spectral imaging color enhancement; OGIB: Obscure gastrointestinal bleeding; OR: Odds ratio; PDI: Polidocanol injection; PHE: Portal hypertensive enteropathy.

\section{Competing interests}

The authors declare that they have no competing interests.

\section{Authors' contributions}

Al designed this study, collected the clinical data, wrote the manuscript and performed the statistical analyses, with contributions from SO, ST and KC. Al, SO, ST, SK, MN and TA participated in the study as physicians who treated and performed follow-up of the patients. All authors read and approved the submission of the final manuscript.

\section{Acknowledgements}

The funding source had no involvement in the design, analysis, or writing of the paper or in the decision to publish this work.

\section{Author details}

'Department of Gastroenterology and Metabolism, Graduate School of Biomedical Sciences, Hiroshima University, Hiroshima, Japan. ${ }^{2}$ Department of Endoscopy, Hiroshima University, 1-2-3 Kasumi, Minami-ku, Hiroshima 734-8551, Japan.

Received: 7 April 2015 Accepted: 13 August 2015

Published online: 25 August 2015 


\section{References}

1. Li F, Leighton JA, Sharma VK. Capsule endoscopy in the evaluation of obscure gastrointestinal bleeding: a comprehensive review. Gastroenterol Hepatol. 2007:3:777-85.

2. Lewis BS. Small intestinal bleeding. Gastroenterol Clin North Am. 1994;23:67-91.

3. Heine GD, Hadithi M, Groenen MJ, Kuipers EJ, Jacobs MA, Mulder CJ. Double balloon enteroscopy: indications, diagnostic yield, and complications in a series of 275 patients with suspected small-bowel disease. Endoscopy. 2006;38:42-8.

4. Jacobs MA, Mulder CJ. Double balloon endoscopy in GI hemorrhage. Gastrointest Endosc. 2007;66:S60-2

5. Ohmiya N, Yano T, Yamamoto H, Arakawa D, Nakamura M, Honda W, et al. Diagnosis and treatment of obscure Gl bleeding at double balloon endoscopy. Gastrointest Endosc. 2007;66:S72-7.

6. Schmit A, Gay F, Adler M, Cremer M, Van Gossum A. Diagnostic efficacy of push-enteroscopy and long-term follow-up of patients with small bowel angiodysplasias. Dig Dis Sci. 1996:41:2348-52.

7. Yano T, Yamamoto H, Sunada K, Miyata T, Iwamoto M, Hayashi Y, et al. Endoscopic classification of vascular lesions of the small intestine (with videos). Gastrointest Endosc. 2008;67:169-72

8. Fan GW, Chen TH, Lin WP, Su MY, Sung CM, Hsu CM, et al. Angiodysplasia and bleeding in the small intestine treated by balloon-assisted enteroscopy. J Dig Dis. 2013;14:113-6.

9. Li X, Chen H, Dai J, Gao Y, Ge Z. Predictive role of capsule endoscopy on the insertion route of double-balloon enteroscopy. Endoscopy. 2009;41:762-6.

10. Regula J, Wronska E, Pachlewski J. Vascular lesions of the gastrointestinal tract. Best Pract Res Clin Gastroenterol. 2008;22:313-28.

11. Junquera F, Saperas E, de Torres I, Vidal MT, Malagelada JR. Increased expression of angiogenic factors in human colonic angiodysplasia. Am J Gastroenterol. 1999:94:1070-6.

12. Roskell DE, Biddolph SC, Warren BF. Apparent deficiency of mucosal vascular collagen type IV associated with angiodysplasia of the colon. J Clin Pathol. 1998:51:18-20.

13. Heyde EC. Gastrointestinal bleeding in aortic stenosis. N Engl J Med. 1958;259:196.

14. Chalasani N, Cotsonis G, Wilcox CM. Upper gastrointestinal bleeding in patients with chronic renal failure: role of vascular ectasia. Am J Gastroenterol. 1996;91:2329-32.

15. Rosborough TK, Swaim WR. Acquired von Willebrand's disease, platelet-release defect and angiodysplasia. Am J Med. 1978;65:96-100.

16. De Palma GD, Rega M, Masone S, Persico F, Siciliano S, Patrone F, et al. Mucosal abnormalities of the small bowel in patients with cirrhosis and portal hypertension: a capsule endoscopy study. Gastrointest Endosc. 2005;62:529-34.

17. Akyuz F, Pinarbasi B, Ermis F, Uyanikoglu A, Demir K, Ozdil S, et al. Is portal hypertensive enteropathy an important additional cause of blood loss in portal hypertensive patients? Scand J Gastroenterol. 2010;45:1497-502.

18. Aoyama T, Oka S, Aikata H, Nakano M, Watari I, Naeshiro N, et al. Small bowel abnormalities in patients with compensated liver cirrhosis. Dig Dis Sci. 2013;58:1390-6.

19. Aoyama T, Oka S, Aikata H, Igawa A, Nakano M, Naeshiro N, et al. Major predictors of portal hypertensive enteropathy in patients with liver cirrhosis. J Gastroenterol Hepatol. 2015;30:124-30.

20. Mylonaki M, Fritscher - Ravens A, Swain P. Wireless capsule endoscopy: a comparison with push enteroscopy in patients with gastroscopy and colonoscopy negative gastrointestinal bleeding. Gut. 2003;52:1122-6.

21. Delvaux M, Fassler I, Gay G. Clinical usefulness of the endoscopic video capsule as the initial intestinal investigation in patients with obscure digestive bleeding: validation of a diagnostic strategy based on the patient outcome after 12 months. Endoscopy. 2004:36:1067-73.

22. Imagawa H, Oka S, Tanaka S, Noda I, Higashiyama M, Sanomura Y, et al. Improved visibility of lesions of the small intestine via capsule endoscopy with computed virtual chromoendoscopy. Gastrointest Endosc. 2011:73:299-306

23. Imagawa H, Oka S, Tanaka S, Noda I, Higashiyama M, Sanomura Y, et al. Improved detectability of small-bowel lesions via capsule endoscopy with computed virtual chromoendoscopy: a pilot study. Scand J Gastroenterol. 2011;46:1133-7.

24. Maeda M, Hiraishi H. Efficacy of video capsule endoscopy with flexible spectral imaging color enhancement at setting 3 for differential diagnosis of red spots in the small bowel. Dig Endosc. 2014;26:228-31.
25. Shishido T, Oka S, Tanaka S, Aoyama T, Watari I, Imagawa H, et al. Diagnostic yield of capsule endoscopy vs. double-balloon endoscopy for patients who have undergone total enteroscopy with obscure gastrointestinal bleeding. Hepatogastroenterology. 2012;59:955-9.

26. Postgate A, Despott E, Burling D, Gupta A, Phillips R, O'Beirne J, et al. Significant small-bowel lesions detected by alternative diagnostic modalities after negative capsule endoscopy. Gastrointest Endosc. 2008;68:1209-14.

27. Jensen LS, Dybdahl H, Juhl C, Nielsen TH. Endoscopic sclerotherapy of esophageal varices in an experimental animal model. A histomorphologic study. Scand J Gastroenterol. 1986;21:725-32.

28. Soehendra N, Grimm H, Stenzel M. Injection of nonvariceal bleeding lesions of the upper gastrointestinal tract. Endoscopy. 1985;17:129-32.

29. Okano H, Nishida H, Imamura M, Uchida S, Horiguchi Y, Sato T, et al. Endoscopic local injection of Aethoxysklerol to upper gastrointestinal bleeding. Gastroenterol Endosc. 1986;28:1233-6 [Article in Japanese].

30. Takeuchi $T$, Narimiya $N$, Joki M, Iwasaki M, Sugimoto I, Watanabe $T$, et al. Experimental study on the effects of local injection of Aethoxysklerol for gastric mucosa with special reference to the submucosal arterial plexus. Gastroenterol Endosc. 1991;33:695-704 [Article in Japanese].

31. Rahmi G, Samaha E, Vahedi K, Delvaux M, Gay G, Lamouliatte H, et al. Long-term follow-up of patients undergoing capsule and double-balloon enteroscopy for identification and treatment of small-bowel vascular lesions: a prospective, multicenter study. Endoscopy. 2014:46:591-7.

\section{Submit your next manuscript to BioMed Central and take full advantage of:}

- Convenient online submission

- Thorough peer review

- No space constraints or color figure charges

- Immediate publication on acceptance

- Inclusion in PubMed, CAS, Scopus and Google Scholar

- Research which is freely available for redistribution 